\title{
The underdog mechanical alternative for tailings dewatering: the screw press
}

\author{
W Wimmler Innovative Filtration Solutions Pty Ltd, Australia \\ S Whitton Mechanical Advantage Pty Ltd, Australia \\ L Wimmler Innovative Filtration Solutions Pty Ltd, Australia
}

\begin{abstract}
"Given the increasing scrutiny of the mining industry and its relatively poor record with regards to mine tailings management, increased requirements to minimise water usage (often accompanied by very high costs of water) and the need to demonstrate achievable long-term closure strategies, it is likely that the option of a filtered tailings system will need to be considered in many operations in future." (Australian Centre for Geomechanics 2018).

Given such a statement as a conference introduction, it is only appropriate that a range of potential technologies are investigated and compared, to create awareness for even underrated but appropriate technologies. The advantages and disadvantages of all technologies need to be considered and analysed. Suppliers are swift to promote their technologies advantages, however aspects of sustainability are not always fully understood and comprehended. Perhaps a combination of two filtration technologies is appropriate. This paper delves into the technical details, good or bad, of four mechanical dewatering technologies in tailings dewatering and provides insight on an undervalued and, in the author's opinion, young technology - the screw press.
\end{abstract}

Keywords: screw press, tailings, dewatering, filtration, waste water

\section{Introduction}

This paper contains:

- A brief overview of mechanical tailings dewatering processes that have been used in Australia and their relative performance and operating parameters, capital and operating cost.

- An overview of the relationship between dewatered tailings moisture, shear strength and safe transportation and deposition methods.

- How screw press filtration fits into the overall fabric of the tailings dewatering and disposal system.

- A high level comparison of the capital and operating costs of a screw press filtration plant and a pressure filtration plant.

This is an overview of mechanical tailings dewatering in the context of Australian industry - which has, for some 30 years, been either under-investigated or under-utilised.

Tailings dewatering cannot be and should not be considered in isolation from the rest of the tailings creation, dewatering, handling, deposition and rehabilitation processes, as its product affects all downstream stages. A holistic approach is required for the entire mining operation when considering the appropriate handling of tailings. 


\section{$2 \quad$ Tailings dewatering processes}

A large number of potential dewatering systems exist and are used for tailings. These include:

- Natural sedimentation - tailings dams.

- Desiccation - evaporation.

- Aided or enhanced sedimentation - flocculated tailings dams, conventional and high-rate thickeners, centrifugation.

- Filtration - vacuum drum, disk and belt, belt press, diaphragm recess plate (membrane) press, tower pressure and continuous hyperbaric filtration and geo-tubes.

In mining operations, the beneficiation process is typically followed by the thickening of tailings utilising either conventional or high-rate thickeners, the thickener feed being typically between $8 \%$ and $12 \%$ solids concentration. It is understood that this process may not be necessary in some minerals or metallurgical operations where the tailings produced by the beneficiation process is at a far higher solids concentration.

Mechanical dewatering processes have been applied to both tailings and ultra-fine product in both the coal and metallurgical mining industries. These processes include:

- Belt press filters.

- Pressure filters.

- Recess plate pressure filters, with or without diaphragms (membranes).

- Tower presses.

- Hyperbaric filters.

- Vacuum drum, disc and belt filters.

- Centrifuges.

Many of these technologies have been applied successfully to the filtration of mine-produced concentrates and hydrometallurgical plant precipitates. The coal industry applies a number of these technologies to the dewatering of fine coal concentrate as produced by flotation. The alumina industry uses pressure and disk filters.

Some of these technologies have been applied to the tailings streams from metalliferous processes.

A comparison of these technologies and their operating history in Australia is summarised in the following section.

\subsection{Belt press filters}

Belt presses are still widely used, e.g. for coal tailings dewatering with a moderate level of success. The key features are:

- Continuous operation.

- Low unit throughput.

- Large, throughput specific footprint.

- High wash water consumption.

- High flocculant consumption.

- High sensitivity to changes in feed conditions.

- Moderate to high product moisture.

- Poor to moderate cake quality and handleability.

- Moderate water recovery.

- Moderate equipment availability. 
- A high need of operator input.

- High maintenance cost.

\subsection{Recess plate pressure filters}

Pressure filters for tailings are utilised in various industries but predominantly in the alumina and iron ore mining industries. The approach has been implemented in some locations in Australia for coal tailings dewatering and was found to be sub-optimal. The reasons for their failure, to date, include inappropriate equipment selection and, more importantly, a lack of understanding of the properties of the feed, the varying nature of those properties and its filtration performance. It should be noted that this technology has been successfully applied to coal tailings in South Africa and China. The key features are:

- Batch operation.

- Large, throughput specific footprint.

- Relatively high unit throughput.

- Low to no flocculant consumption.

- Low product moisture.

- Good cake quality and handleability.

- High sensitivity to changes in feed conditions.

- High level of water recovery.

- Medium wash water consumption.

- Low equipment availability for conventional filter press designs.

- If the appropriate equipment is utilised, a low need for operator input.

- High capital cost.

\subsection{Vacuum belt filters}

Vacuum belt filters applied in some industries have not been particularly successful. This is because vacuum filters are only viable for coarse materials and not for fines and ultra-fines. The key features are:

- Continuous operation.

- Medium unit throughput.

- High flocculant consumption.

- High product moisture.

- Poor cake quality and handleability.

- Large footprint.

- Moderate water recovery.

- Low need for operator input.

\subsection{Solid bowl centrifuges}

Solid bowl centrifuges were applied relatively widely to tailings dewatering in the Australian coal industry during the 1980s. They have been applied seldomly since then, however, recently a number of decanters or centrifuges are being utilised in the industry. The key features are:

- Continuous operation.

- Low unit throughput.

- Medium flocculant consumption.

- High power consumption.

- Very high maintenance cost. 
- Moderate cake moisture.

- Poor cake quality and handleability.

- Moderate water recovery.

- Low need for operator input.

It should be noted that current available devices utilising this technology with increased gravitational-forces applied, have increased unit capacity over those that were employed in the 1980 s.

\subsection{Screw presses}

Screw presses is a relatively unknown dewatering equipment in the tailings industry, with only one installation in the world thus far. In waste water and water treatment, however, there are approximately 600 new installations every year, replacing other technologies such as belt presses, filter presses, and centrifuges. The key features are:

- Continuous operation.

- Low to medium unit throughput.

- High flocculant consumption.

- Very low power consumption.

- Very low maintenance cost.

- Moderate cake moisture.

- Good cake quality and handleability.

- Moderate water recovery.

- Low need for operator input.

\subsection{Disposal alternatives}

There are several disposal methods of tailings used in Australia. Currently, most do not necessarily involve mechanical dewatering.

- Pumped co-disposal.

- Flocculated tailings dam or secondary flocculation.

- Geo-tubes.

- Dry stacking.

- Paste backfill.

\subsection{Qualitative comparison}

The key obstacle for all applied technologies is the very high cost of maintenance for what is waste material and not product. Solid bowl centrifuges require continuous replacement of rotating parts. Pressure filters, belt filter presses and horizontal belt vacuum filters require frequent filter cloth changes.

This is one of the major reasons to employ the screw press technology. In waste water application, screw presses have been applied successfully for the past 30 years.

These unit processes are summarised and compared qualitatively in Table 1. 


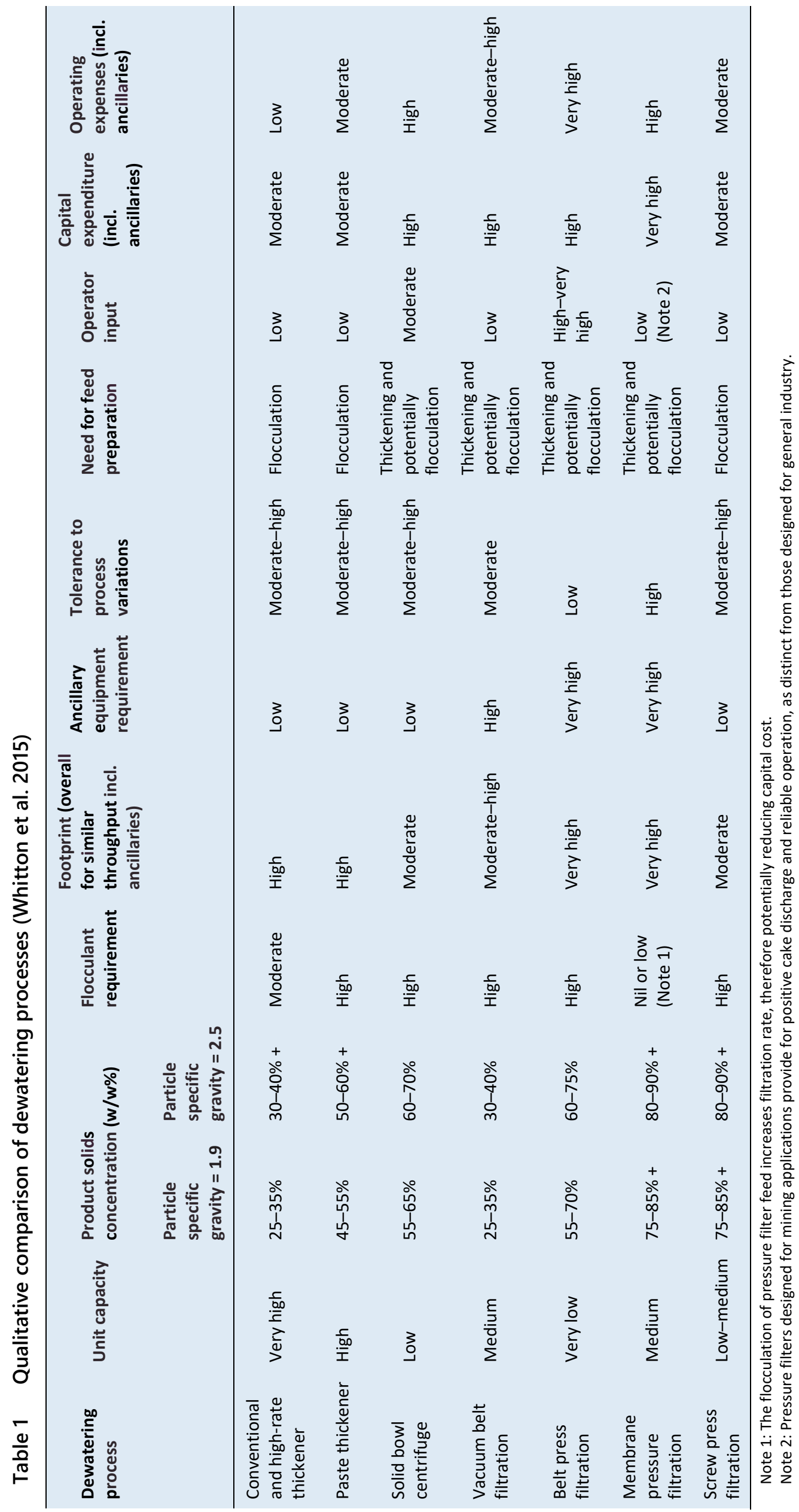




\section{Dewatered tailings transportation and disposal}

The mechanical dewatering process is just one part of a multi-stage process culminating in the creation of a stable tailings deposit that is safe and able to be rehabilitated in a cost-effective manner. It should therefore, not be considered in isolation from the rest of the tailings creation, dewatering, handling, deposition and rehabilitation processes, as its product affects all downstream stages. The complete tailings handling process is typically considered to start at the discharge of the beneficiation processes but, depending on composition, it may actually start in the mine. If materials are present in the mine, whose inclusion in the tailings result in significant increases in the difficulty and cost of dewatering, transportation, disposal and rehabilitation, it may be more efficient to exclude them from the beneficiation plant feed by way of selective mining. Additionally, in some cases, the selection and/or operation of beneficiation processes may greatly improve tailings processing.

As the end game of tailings processing is the creation of an emplacement that is safe and easy to rehabilitate, it is often beneficial to consider the entire process, starting from the tailings emplacement and working backward along the dewatering system process train, thus choosing the mechanical dewatering system last. This approach, considering each step of the tailings handling process, starting at the deposit, may be summarised as follows:

- Design a tailings emplacement in line with the considerations discussed above.

- Once the deposition process has been selected, the method of transportation from the dewatering process to the deposit can be selected, such that it delivers the tailings in a form that suits the deposition process, in a safe and reliable manner. This step is often the most difficult to satisfy.

- A dewatering process can then be selected that will deliver properties that suit both the deposit design and the transportation process.

To a large degree, the unique property for each tailings material that governs how it responds to both deposition and transportation is its shear strength, which in turn depends on its moisture content. A typical qualitative relationship between shear strength and moisture content for a hypothetical tailings material is illustrated as in Figure 1.

Figure 1 shows that the shear strength of a granular material changes as its moisture content increases, reaching a maximum before it slowly falls to zero at high moisture content.

The qualitative relationship between the various moisture content zones shown in Figure 1 and material properties, handleability, water recovery, rehabilitation, capital, operating and rehabilitation costs is shown in Table 2.

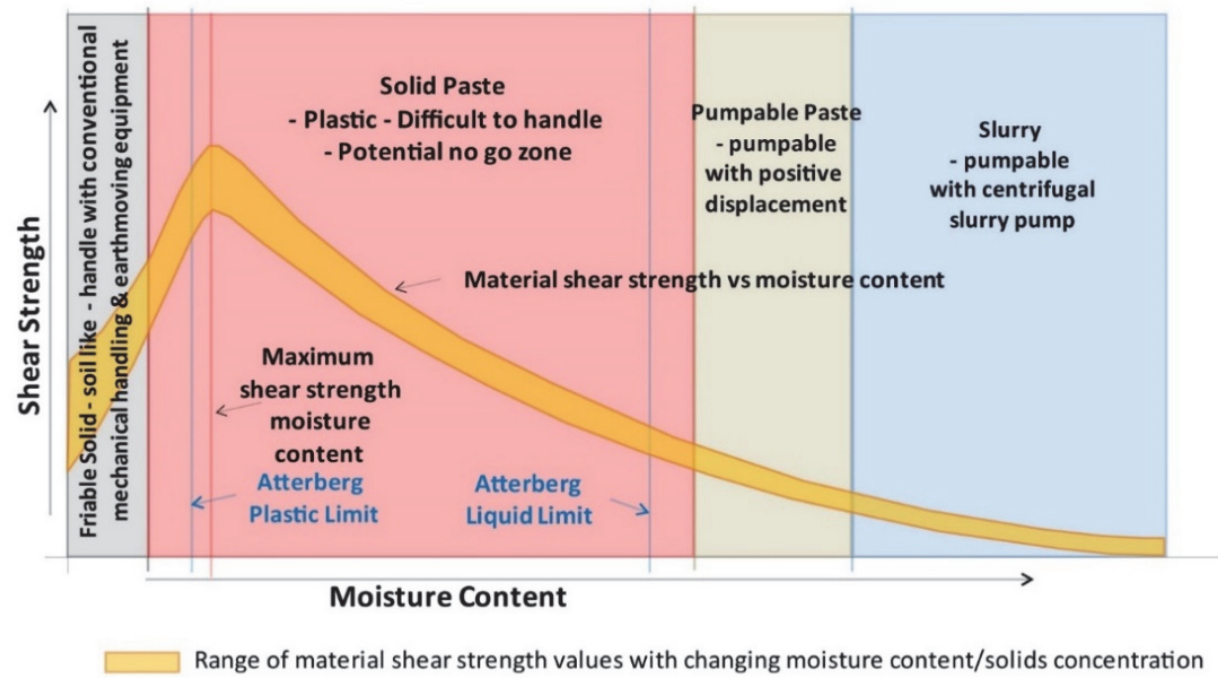

Figure 1 Solid paste to plastic paste (Whitton et al. 2015) 
Table 2 Paste attributes (Whitton et al. 2015)

\begin{tabular}{|c|c|c|c|c|c|c|c|}
\hline $\begin{array}{l}\text { Moisture } \\
\text { range }\end{array}$ & $\begin{array}{l}\text { Material } \\
\text { behaviour }\end{array}$ & $\begin{array}{l}\text { Transportation } \\
\text { method }\end{array}$ & $\begin{array}{l}\text { Water } \\
\text { recovery }\end{array}$ & Rehabilitation & $\begin{array}{l}\text { Capital } \\
\text { expenditure }\end{array}$ & $\begin{array}{l}\text { Operating } \\
\text { expenses }\end{array}$ & $\begin{array}{l}\text { Rehabilitation } \\
\text { cost }\end{array}$ \\
\hline & $\begin{array}{l}\text { Friable } \\
\text { soil like }\end{array}$ & $\begin{array}{l}\text { Belt conveyors, } \\
\text { bins, } \\
\text { earthmoving } \\
\text { equipment }\end{array}$ & $\begin{array}{l}\text { Good, } \\
\text { easy to } \\
\text { manage }\end{array}$ & $\begin{array}{l}\text { Easy to } \\
\text { achieve, in } \\
\text { mine waste }\end{array}$ & $\begin{array}{l}\text { Moderate } \\
\text { to high }\end{array}$ & $\begin{array}{l}\text { Low to } \\
\text { moderate }\end{array}$ & Low \\
\hline & $\begin{array}{l}\text { Plastic } \\
\text { paste }\end{array}$ & $\begin{array}{l}\text { Difficult and } \\
\text { unreliable, } \\
\text { attempt to use } \\
\text { belt conveyors } \\
\text { and } \\
\text { earthmoving } \\
\text { equipment }\end{array}$ & $\begin{array}{l}\text { Moderate } \\
\text { to good }\end{array}$ & $\begin{array}{l}\text { Easy if in mine } \\
\text { waste, } \\
\text { extremely } \\
\text { difficult if } \\
\text { tailings } \\
\text { storage } \\
\text { facility }\end{array}$ & $\begin{array}{l}\text { Moderate } \\
\text { to high }\end{array}$ & $\begin{array}{l}\text { Moderate } \\
\text { to high }\end{array}$ & $\begin{array}{l}\text { Low if in mine } \\
\text { waste, } \\
\text { extremely } \\
\text { high if tailings } \\
\text { storage } \\
\text { facility }\end{array}$ \\
\hline & $\begin{array}{l}\text { Pumpable } \\
\text { paste }\end{array}$ & $\begin{array}{l}\text { High pressure } \\
\text { positive }\end{array}$ & $\begin{array}{l}\text { Poor to } \\
\text { moderate }\end{array}$ & $\begin{array}{l}\text { Moderate to } \\
\text { extremely } \\
\text { difficult }\end{array}$ & High & High & $\begin{array}{l}\text { High to } \\
\text { extremely } \\
\text { high }\end{array}$ \\
\hline & Slurry & $\begin{array}{l}\text { Low pressure } \\
\text { centrifugal } \\
\text { slurry pump }\end{array}$ & $\begin{array}{l}\text { Poor, } \\
\text { difficult } \\
\text { to } \\
\text { manage }\end{array}$ & $\begin{array}{l}\text { Moderate to } \\
\text { extremely } \\
\text { difficult }\end{array}$ & Low & $\begin{array}{l}\text { Low to } \\
\text { moderate }\end{array}$ & $\begin{array}{l}\text { High to } \\
\text { extremely } \\
\text { high }\end{array}$ \\
\hline
\end{tabular}

With regards to Table 2, and considering the entire tailings handling train from dewatering to deposit rehabilitation, there are few moisture ranges that provide reliable and manageable transportation and deposition options that aid rehabilitation, regardless of cost and water recovery.

The practical aspects of transportation and deposition have been investigated already and are not part of this consideration.

There are few mechanical dewatering processes that will achieve the low cake moisture contents necessary to satisfy the conditions required for dry stacking. These dewatering systems include the recessed chamber as well as diaphragm press pressure filtration, centrifuges and screw press filtration.

\section{Screw press filtration}

The screw press is a continuous dewatering device. A screw is installed between the two bearing housings, which are situated in the main frame. This screw is surrounded by the filter screen which is attached to the main frame of the screw press. Slurry enters the screw press, between the screw and the screen, where the solid matter is separated from the filtrate water. The filtrate flows through the perforated screen and is collected by the drip tray. The solid matter is slowly conveyed through the press with an internal rotating screw, driven by a gear motor. Additionally, the screw is also equipped with a replaceable scraper which cleans the inner surface of the filter screen. Figure 2 depicts a cutaway of such a screw press in three dimensions while Figure 3 reveals the cross section via cut away.

The screw and filter screen are enclosed to contain odours and aerosols, as well as sprays and prevent spills. Access hatches on both sides of the filter cover allow for access and viewing. A washing device, which includes multiple washing nozzles, is contained in the enclosure to rinse the filter screen and the inside of the cover regularly, or on demand, using service water. The washing nozzles are installed on a circular tube that moves horizontally over the full length of the filter screen by means of a linear drive, which is pneumatically actuated. During the washing of the filter screen, the dewatering process is not interrupted. 


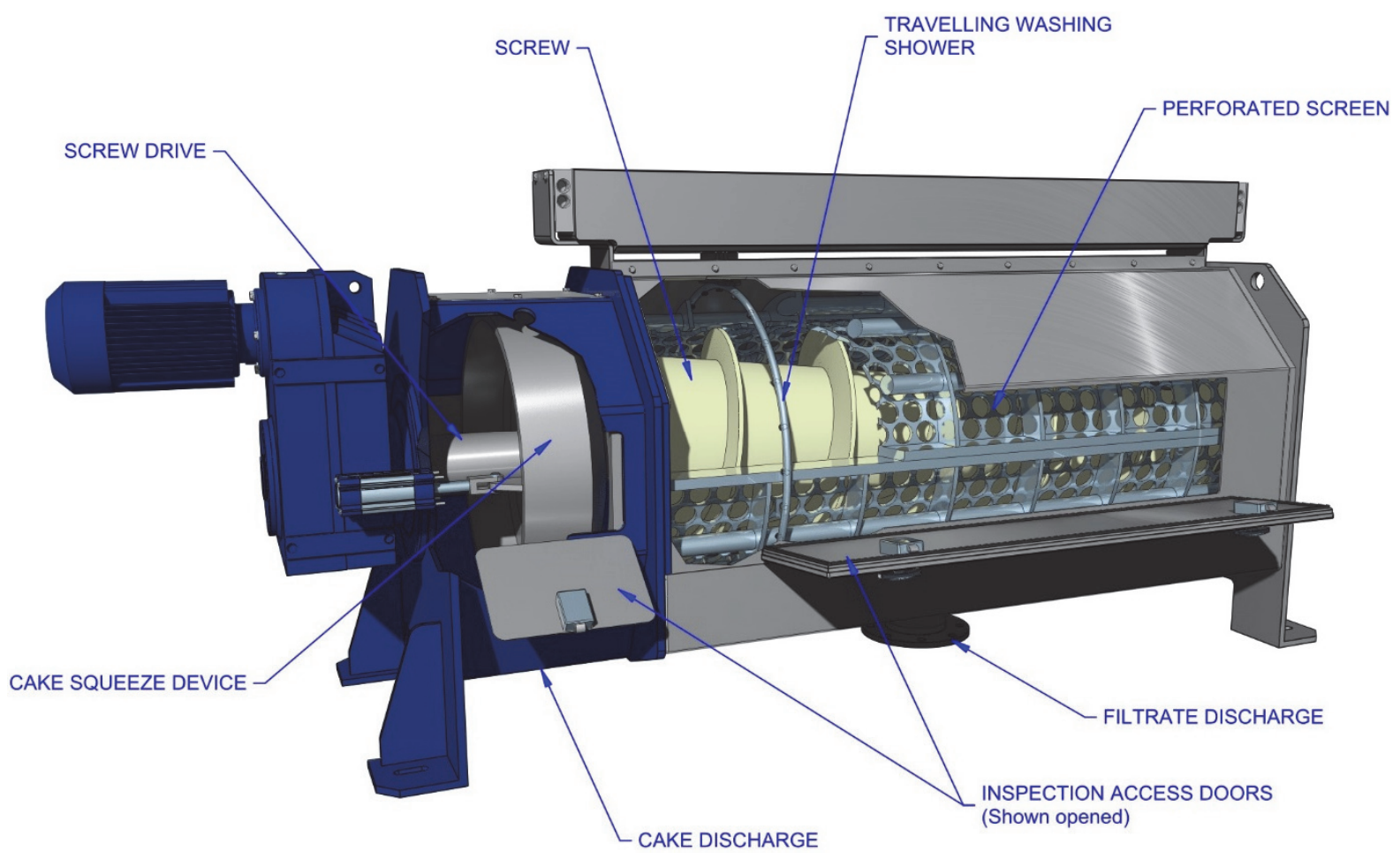

Figure 2 Cutaway illustration of a screw press (IEA Derflinger $\mathrm{GmbH}$ )

The screw press filter screen is split into three sections. In the first is an open pore designed for high flow where the majority of the filtrate is discharged. The second section, the filtration section, has smaller holes and the final section, the pressing section, where squeezing of the cake occurs, has even finer holes. The slurry cake is discharged at the end of the screw press, where a presser cone is situated. This presser is used to push against the discharge, achieved by pneumatic cylinders, to remove further filtrate and obtain a drier cake.

Preparing the slurry to the correct degree of flocculation is important. This is aided by the conditioning tank that allows the flocs to grow and develop accordingly. Variable agitation in the conditioning tank assists the development of the flocculation of the suspended solids. The slurry enters the tank at the base and exits the tank via the top directly into the screw press. The efficiency of the dewatering is determined by the composition of slurry, the degree of flocculation, the speed of the screw and finally the pressure on the presser at the end of the unit. The process flow diagram for the screw press is included in Figure 4.

Screw press filters were introduced into the waste water treatment industry some 20 years ago and have been successfully applied in water and waste water treatment, and the paper and chemical industries.

In many applications, screw press filters are replacing, or have totally replaced belt press filters, most especially where ultra-fine solids and clays are present.

When compared to other types of filtration processes, the advantage and key features that screw press filters provide are:

- Medium to high unit throughput, approximately $50 \mathrm{t} / \mathrm{hr}$, however, this depends on the required solids concentration output. By requiring lower solids concentration a significantly higher throughput can be achieved.

- Low rotational speed (1-2 rpm) - no dynamic loads.

- Mechanical simplicity having few slow-moving parts and no fabric filter cloths.

- Low cost installation and maintenance.

- Low wash water consumption. 
- Continuous operation.

- Low power usage (low carbon footprint).

- Stable operation.

- Reagent consumption that is comparable to that of other flocculant consuming dewatering processes.

- Low shearing of the flocculated solids.

- High hydraulic capacity when compared to other forms of filtration. In some instances, a screw press only could be used to replace a thickening device in conjunction with a filter, which means the thickening device can be made obsolete.

- Filter cake solids concentrations greater than $90 \%$.

- Filter cake with good handling characteristics.

- Comparatively small footprint (the size of installation).

- A wide range of feed concentration can be applied (1-50\%).

The first screw press in a mining application is in operation at Lake Vermont coal mine in Queensland, Australia.

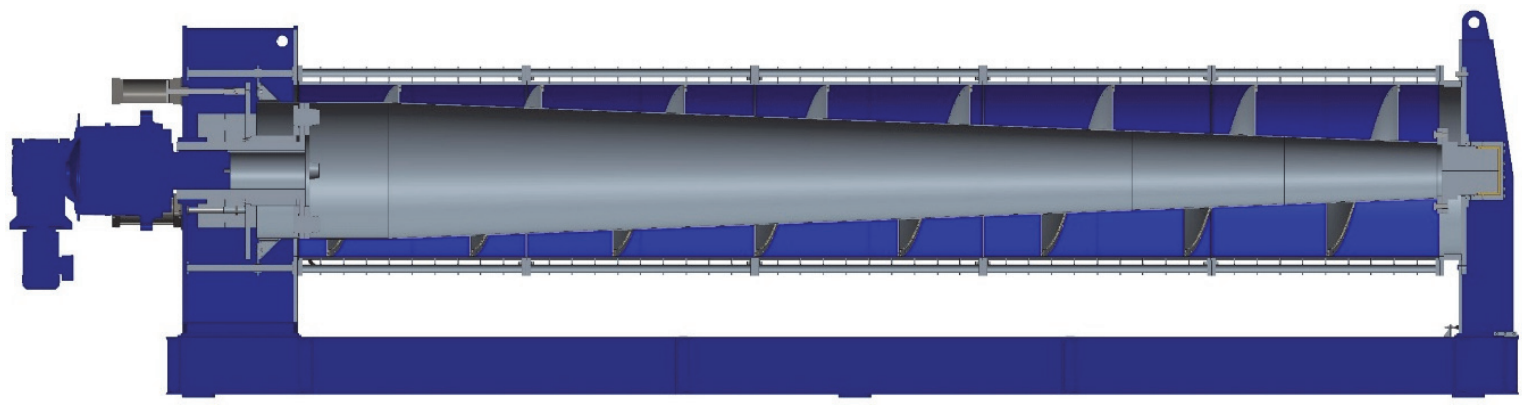

Figure 3 Cutaway illustration of the screw geometry

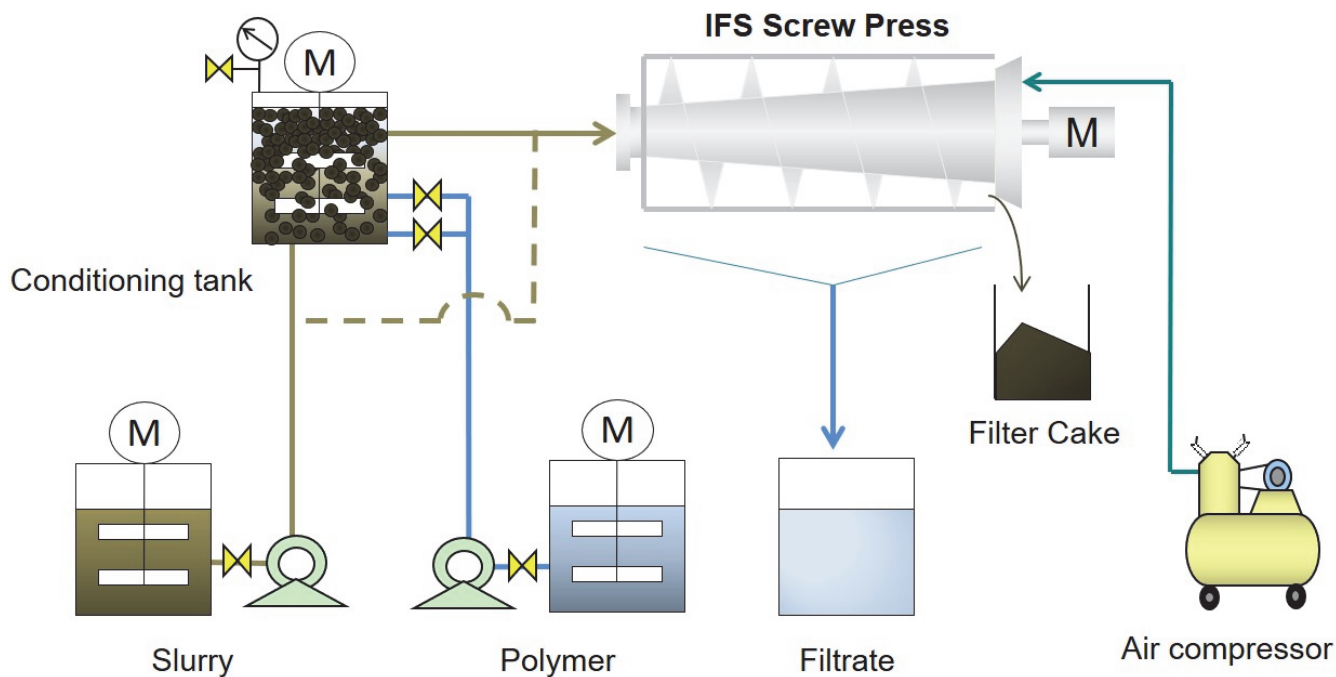

Figure 4 Process flow diagram for the screw press 


\section{$5 \quad$ Case studies}

The following is a cost comparison between a screw press filter and a membrane pressure filter installation. The equipment selections are based on a feed of $100 \mathrm{t} / \mathrm{hr}$ of solids from a coal mine with a specific gravity of 2.6 , in the form of a slurry with water, at a solid concentration of $26 \%$ by mass.

Three options are considered, including equipment such as tanks, pumps conveyors, floc preparation and transfer, clad filter house with overhead crane; concrete; pipework and valves; electrics and instrumentation; engineering, procurement and construction management (EPCM); contractors' profit and $10 \%$ contingency.

- Option 1: $24 \mathrm{~m}$ high-rate thickener $+2 \times$ fully automated filter press (Lasta, Outotec, Metso).

- Option 2: $24 \mathrm{~m}$ high-rate thickener $+2 \times$ fully automated IEA screw press SP13M.

- Option 3: 2 × fully automated IEA screw press SP13M.

\section{$5.1 \quad$ Utilisation}

Depending on the type of filtration unit installed, the equipment availability of a filter press can be stated as being between $70 \%$ (vertical pressure filters) and $92 \%$ (fully automated horizontal pressure filters). Conventionally designed filter presses may only achieve up to $80 \%$ availability, however, this is extremely manufacturer specific.

In contrast to a batch operating pressure filter, the screw presses availability is well above $95 \%$, usually at 98\%. The screw press has no filter cloth or filter media to be replaced (IEA Derflinger Gmbh 2018).

\subsection{Capital cost estimates}

Capital cost estimates for the three options are as follows (Whitton et al. 2015):

- Option 1: AUD 24M = AUD 240,000/t/hr.

- Option 2: AUD 10.5M = AUD 105,000/t/hr.

- Option 3: AUD 5.5M = AUD 55,000/t/hr.

These costs are based on Australian market conditions in 2014 and priced in Australian dollars (Whitton et al. 2015).

\subsection{Operating cost estimates}

Operating cost estimates for the three options are summarised in Table 3 and include (Whitton et al. 2015):

- Electrical power consumption at AUD 0.09/kWh.

- Allowance for the maintenance of mechanical equipment including the periodic replacement of filter cloths and filter plates for the pressure filter and filter screens and screw for the screw press.

- Allowances for the maintenance of concrete, structures, platework, pipework, electrical equipment and instrumentation.

- Consumables and flocculants, the latter at estimated rates that are considered typical for this type of feed.

- Additional manning as considered necessary. Manning is costed at AUD 150,000/annum. 
Table 3 The operating cost estimates for each option are (Whitton et al. 2015)

\begin{tabular}{|c|c|c|c|}
\hline Operating cost & Option 1 & Option 2 & Option 3 \\
\hline Filter & AUD 1.14 & AUD 0.41 & AUD 0.41 \\
\hline $\begin{array}{l}\text { Maintenance of other } \\
\text { plant and equipment }\end{array}$ & AUD 0.85 & AUD 0.27 & AUD 0.08 \\
\hline Consumables & AUD 0.63 & AUD 1.82 & AUD 1.37 \\
\hline Power & AUD 0.78 & AUD 0.24 & AUD 0.15 \\
\hline Labour & AUD 0.41 & AUD 0.04 & AUD 0.02 \\
\hline Total & AUD 3.81/t/hr & AUD $2.78 / \mathrm{t} / \mathrm{hr}$ & AUD $2.04 / \mathrm{t} / \mathrm{hr}$ \\
\hline
\end{tabular}

\subsection{Performance}

The handleability of the filter cake produced by the screw press is comparable to that of the filter press with no moisture release during cake transportation. The filter press outperforms the screw press as the solid capture in the filtrate is generally $90 \%+$. This can be improved by incorporating a simple polishing system. The solid losses in the screw press are across the entire spectrum of the particle size distribution, hence there are no increase of circulating ultra-fine loads.

The moisture content of a filter cake produced by a screw press is usually $3-5 \%$ below a diaphragm squeeze filter press. Figures 5 to 7 display the filter cake from a screw press which achieved a moisture content of $55 \%$ to a maximum of $62.4 \%$ dry solids ( $\mathrm{w} / \mathrm{w}$ ) (Wimmler 2015). The filtrate clarity from the screw press test can be seen in Figure 8. This test work was conducted on rare earth tailings in Western Australia (Wimmler 2015).

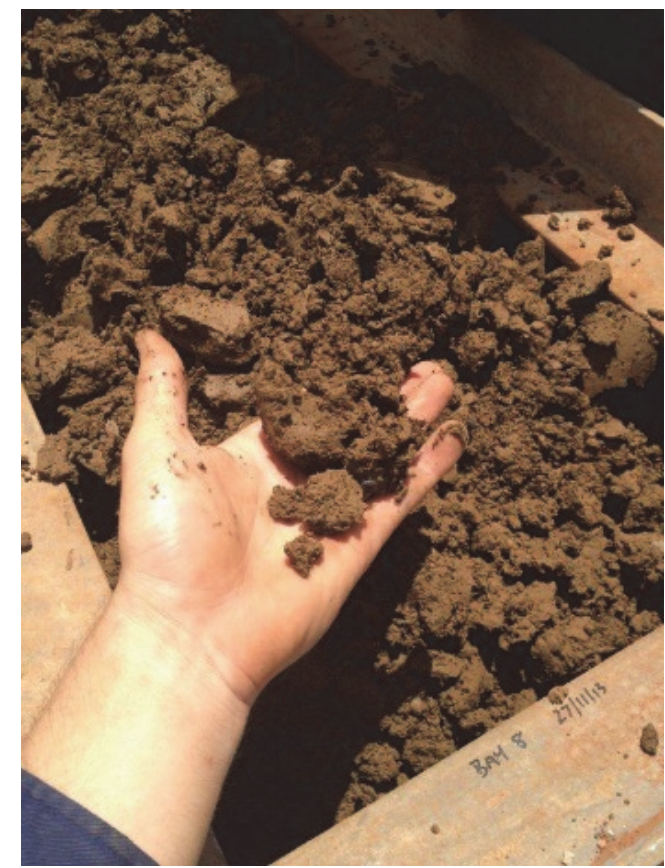

Figure 5 Rare earth filter cake

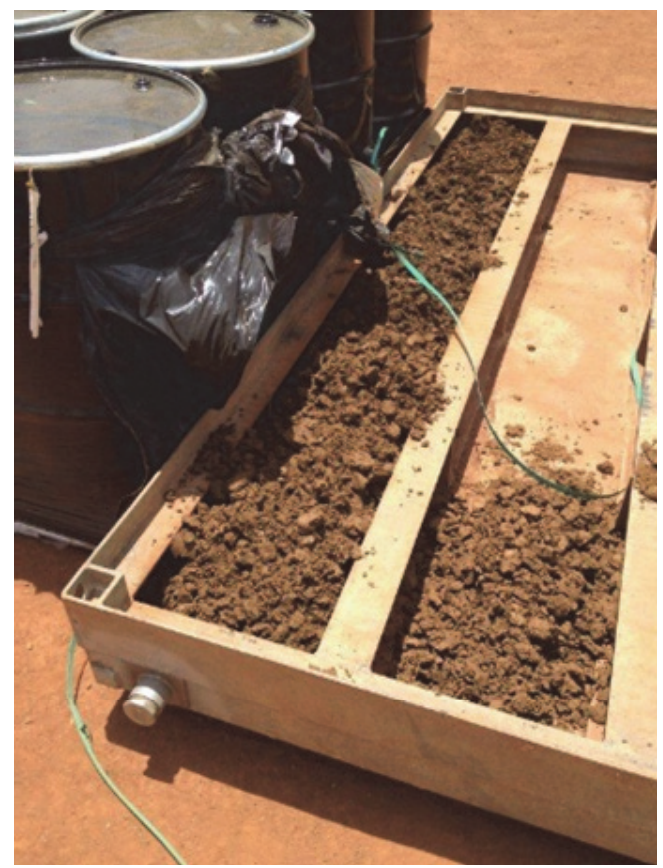

Figure 6 Filter cake sample 


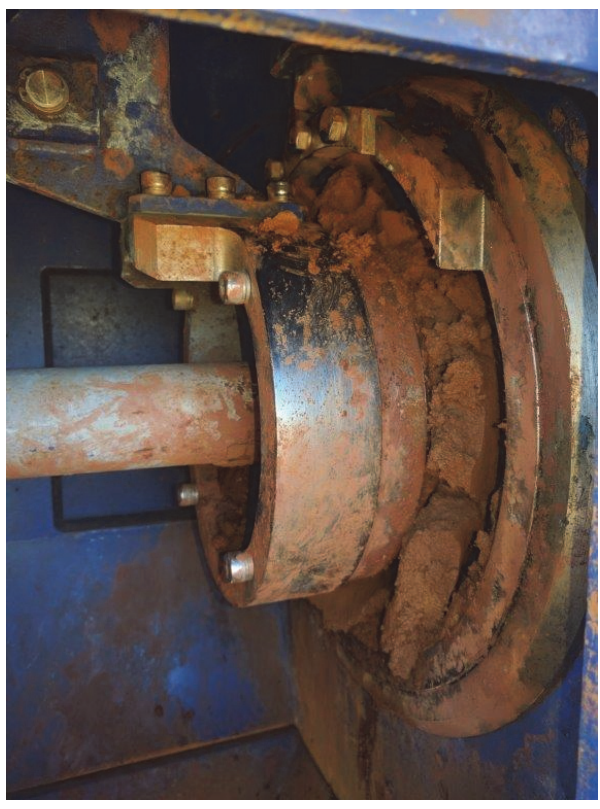

Figure $7 \quad$ Filter cake discharge

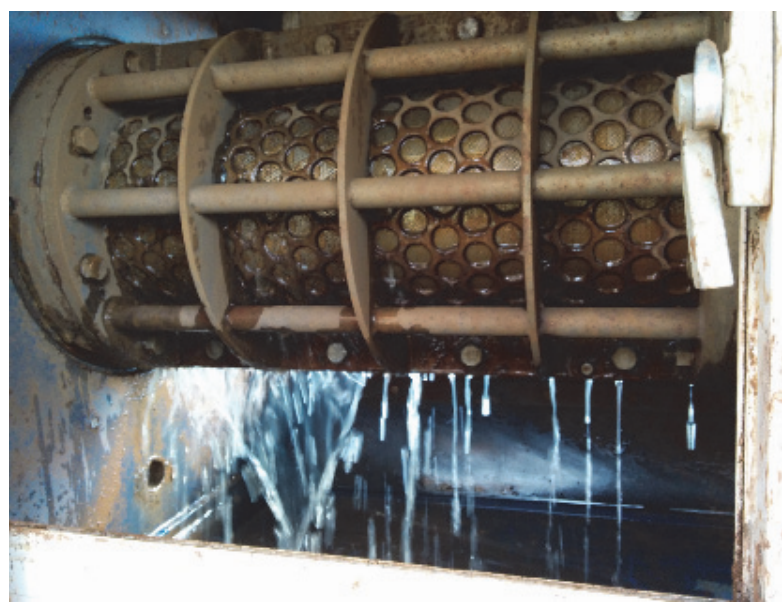

Figure 8 Filtrate clarity

\section{Conclusion}

New solutions for the dewatering of tailings are being investigated as dewatering and waste management in the mining sector has greatly increased in importance. This leads to a sustainable solution driven by water recovery, process robustness, versatility, continuous operation, as well as low carbon footprint in conjunction with low maintenance and operational costs. The best results will be a high priority; however, they will not be the ultimate guidelines. Most future solutions must be practical, sustainable and provide achievable compromises. Research and comparisons of the screw press technology with other filtration technologies illustrated the potential for the screw press to be a viable dewatering technology for tailings.

\section{References}

Australian Centre for Geomechanics 2018, 22nd International Conference on Paste, Thickened and Filtered Tailings Event Brochure, brochure, viewed 21 March 2019, https://www.paste2019.co.za/wp-content/uploads/2018/12/Paste2019_broch_RP_prog.pdf IEA Derflinger Gmbh 2018, Installation, Operating and Maintenance Manual, IEA Derflinger Gmbh, Pucking.

Whitton, S, Wimmler, W \& Vangsness, T 2015, Application of Screw Press Filtration to Tailings Dewatering, The Australian Coal Industry's Research Program, Project Number C23041.

Wimmler, L 2015, 'Screw press dewatering of rare earth flotation tailings', Proceedings of ALTA Uranium-Ree Sessions, ALTA Metallurgical Services, Melbourne. 